\title{
SENSITIVITY \& SPECIFICITY OF SCREENING TOOLS FOR POSTPARTUM DEPRESSION: A SYSTEMATIC REVIEW
}

\author{
Azreena Che Abdullah ${ }^{1}$, Nor Afiah Mohd Zulkefli² ${ }^{*}$, Halimatus Sakdiah Minhat ${ }^{2}$, Anisah Baharom ${ }^{2}$ and \\ Norliza Ahmad² \\ ${ }^{1} \mathrm{DrPH}$ CandidateDepartment of Community Health, Faculty of Medicine \& Health Sciences, Universiti Putra Malaysia, \\ 43400 UPM Serdang, Selangor DarulEhsan, Malaysia. \\ ${ }^{2}$ Department of Community Health, Faculty of Medicine \& Health Sciences, Universiti Putra Malaysia, 43400 UPM \\ Serdang, Selangor DarulEhsan, Malaysia.
}

*CORRESPONDING AUTHOR:Nor Afiah binti Mohd Zulkefli

Email: norafiah@upm.edu.my

\begin{abstract}
Postpartum depression is a depressive episode that can start at any point during the first year after childbirth. There are several tools that can be used for PPD screening. The need to define a predictive tool that is clinically useful and has acceptable sensitivity and sensitivity is important especially to be used in the primary care setting. This systematic review investigates the evidence of the sensitivity and specificity of screening tools used for PPD screening. The Standard for Reporting of Diagnostic Accuracies (STARD) guidelines were used to conduct the review as a basis for our methodology. PubMed, ScienceDirect and Springerlink databases between 2007 until 2017 were comprehensively searched EPDS and BDI instrument has sensitivity of more than $80 \%$ but findings for specificity was inconclusive. The heterogeneity across studies could be the result of methodological differences in validation of the instruments. In addition, these studies were conducted across continents and settings with different cultures, languages and resources. We have identified 5 different instruments used to screen for postpartum depression. The EPDS was the most validated instrument in the review and we found that EPDS and BDI have higher accuracy to screen postpartum depression because the sensitivity reported were more than $80 \%$.
\end{abstract}

Keywords: postpartum depression, screening tool, sensitivity, specificity, EPDS, BDI

\section{INTRODUCTION}

Postpartum depression (PPD) is a depressive episode that can start at any point during the first year after childbirth. PPD may not only affect the mother but it also associated with numerous adverse outcomes in the offspring. These include impaired neonatal growth and development ${ }^{1,2}$, poor cognitive development and behaviour during childhood and even adolescence $e^{1,2,3}$. Besides that, infants of depressed mothers showed significantly more growth retardation as well as negative nutritional where they are at increased risk of diarrheal infection compared with infants of psychologically well mothers ${ }^{4}$.

Postpartum depression (PPD) screening has been made mandatory in developed countries such as in Australia and United States. However, in Malaysia, routine screening for PPD among antenatal mothers have not been introduced in the primary care services. There are several tools that can be used for PPD screening such as Edinburgh Postnatal Depression Scale (EPDS), Patient Health Questionnaire-9 (PHQ-9), Pregnancy Risk Assessment questions (PRAMS-6) and Postpartum Depression Screening Scale (PDSS) ${ }^{5}$. The most widely used for screening of PPD is EPDS tool. The usefulness of a screening tool is evaluated by its sensitivity and specificity ${ }^{25}$. Sensitivity is the true positive rate which means the probability that a patient with a positive test result has the disease and specificity is the true negative rate where the probability that a patient with a negative test result does not have the disease. It is important to define a predictive tool that is clinically useful and has acceptable sensitivity and specificity to be used in the primary care setting. This systematic literature review was conducted to identify the sensitivity and specificity of screening tools for postpartum depression.

\section{METHODOLOGY}

Data sources and search strategy

The Standard for Reporting of Diagnostic Accuracies (STARD) guidelines were used to conduct the review as a basis for our methodology ${ }^{6}$. PubMed, ScrienceDirect and Springerlink databases between 2007 until 2017 were comprehensively searched using variations and combinations of the following MESH and key terms and phrases: "screening" and "screening" [MESH]; "postnatal, depression" [MESH]; "postpartum, depression" [MESH]; "maternal depression" [MESH]; "depression, childbirth" [MESH]; "depression, delivery" [MESH]. Search terms and synonyms were then identified for use in searching different databases for screening studies that were conducted to detect postpartum depression. The search terms used for this review are listed in Table 1. Reference lists from various published articles relevant to this topic were also examined and all articles were imported to Mendeley software. 
Table 1: Search terms

\begin{tabular}{|c|c|}
\hline Database & Terms used \\
\hline PubMed & $\begin{array}{l}\text { "screening tool" and "screening tool" [MESH]; "sensitivity, specificity" [MESH] } \\
\text { "postnatal, depression" [MESH]; "postpartum, depression" [MESH]; "maternal } \\
\text { depression" [MESH]; "depression, childbirth" [MESH]; "depression, delivery" [MESH] }\end{array}$ \\
\hline ScienceDirect & $\begin{array}{l}\text { ALL ("screening instruments" OR “screening tools" OR “screening scale") AND } \\
\text { (postnatal depression OR postpartum depression) OR(woman, maternal, depression, } \\
\text { depression scale, pregnancy, mental health, depressive symptom }\end{array}$ \\
\hline Springerlink & $\begin{array}{l}\text { with all of the words 'postnatal depression', 'postpartum depression', 'maternal } \\
\text { depression', 'screening', with the exact phrase 'depression', with at least one of the } \\
\text { words 'screening' 'validity', without the words 'father', 'paternal' }\end{array}$ \\
\hline
\end{tabular}

\section{Abstract and title screening}

All relevant titles and abstracts were scanned thoroughly by the reviewer. If the abstract did not provide enough information, full text articles were reviewed and if it met the inclusion criteria, the article will be entered in the Excel. Screening of the articles was done based on criteria: Participants: pregnant women at any stage of pregnancy or recently given birth, Index test: the screening instrument, Comparator test: the gold standard which is the psychiatric assessment, Outcome measures: the psychometric properties of the screening instrument which is the sensitivity and specificity.

\section{Inclusion and exclusion criteria}

The inclusion and exclusion criteria for this systematic literature review were structured with the intent of understanding the most effective screening tools used to screen women for postpartum depression. Inclusion criteria include: 1)English-language, 2)self-report measuring tool,3) published within 10 years 2007-2017, 3) aim to examine the validity of self-report depression measure

We excluded articles that did not include postpartum depression as an outcome, articles that did not look postpartum women specifically, incomplete studies, articles that did not have a measurement of postpartum depression and systematic reviews.

Full texts of articles were reviewed for reported validity of depression screening instruments which include sensitivity and specificity and whether a gold standard was present. The articles were independently examined to confirm inclusion. The gold standard was set as a formal diagnostic psychiatric assessment of postpartum depression as the most accurate test to detect the presence or absence of depression. The gold standard includeThe use of the Mini-International Neuropsychiatric Interview (MINI), the Structured Clinical Interview for DSM-IV (SCID), Composite International Diagnostic Interview (CIDI), International Classification of Disease version 10 (ICD-10) or the Diagnostic and Statistical Manual of Mental Disorders version 4 (DSM-IV) by a psychiatrist to assign a diagnosis. The MINI and SCID are compatible with DSM-IV because it has sensitivity and specificity above acceptable level for structured interview which is 0.8 for both. That is why the tools can be referred as gold standard ${ }^{7}$. Instruments that are routinely used for depression such as Edinburgh Postnatal Depression Scale (EPDS) or other nonconventional psychiatric assessment instruments were not considered as gold standards ${ }^{8}$.

Eligibility for full article review, assessment of study characteristics and relevant data extraction was conducted using Excel that included criteria and the confirmation of the presence of psychometric and gold standard. For each eligible study the reviewer extracted information concerning: author, sample size, gold standard, screening instrument, sensitivity and specificity.

\section{Quality Assessment}

The Quality Assessment of Diagnostic Accuracy Studies (QUADAS) was used by reviewer to assess the psychometric quality of the selected articles. QUADAS is intended as an instrument for assessing the quality of previously published studies, especially in the context of systematic literature reviews (ToscanollI, 2011). The QUADAS has 14 items with three possible responses which are 'Yes', 'No', and 'Unclear. In this review for QUADAS, the target condition was postpartum depression, the index test was a screening instrument used to screen depression and reference standard was the gold standard used in the article. The QUADAS item measure the variability of study samples (item 1-2), methodological rigor and bias (items 3-7, 10-12 and 14) and the quality of reporting methodology (items 8, 9 and 13). The scoring of QUADAS is categorised as 'excellent' (11-14 items), 'good' ( 9 -10 items), adequate (6 to 8 items), 'poor' (4 to 5 items) or 'unacceptable' (0 to 3 items) based on the number of items that were answered 'Yes'. For this review three papers were categorized as excellent and six papers were good. The quality assessment is listed in Table 1. 
Table 1: Quality Assessment of the articles reviewed using QUADAS checklist

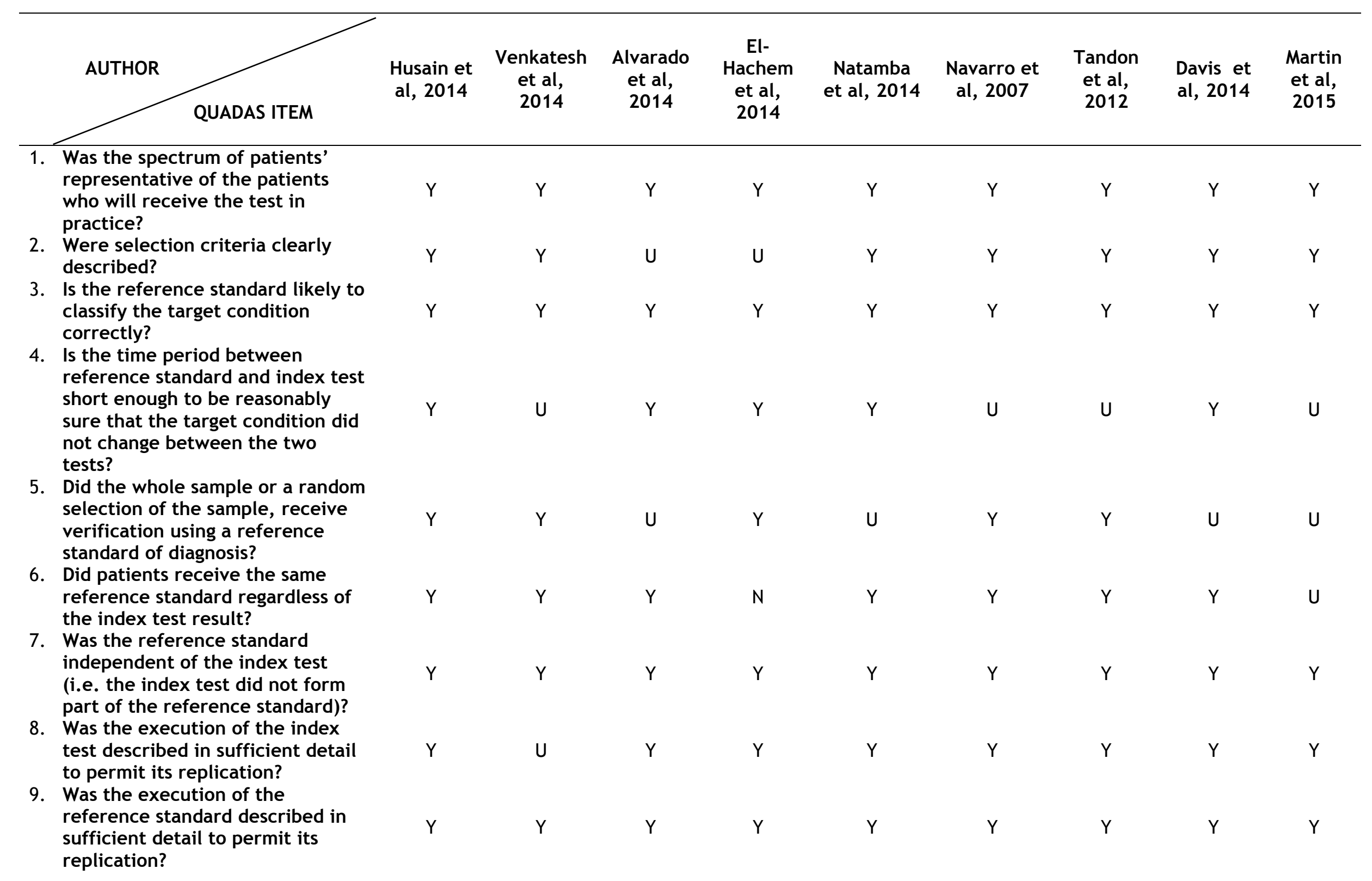


10. Were the index test results interpreted without knowledge of the results of the reference

Y standard?

11. Were the reference standard results interpreted without knowledge of the results of the index test?

12. Were the clinical data available when test results were interpreted the same as when the test would be used in practice?

13. Were uninterpretable or intermediate test results reported?

14. Were withdrawals from the study explained?

$$
\text { Total Score (14) }
$$

\section{Excellent: 11-14}

Good: 9-10

Adequate: 6-8

Poor: 4-5

Unacceptable: 0-3

U

Y

U
U

U

Y

U

Y

Y

Y

U

Y

Y

U

Y

U

Y

Y

Y

U

U

U

U

U

U

U

U

Y

Y

Y

Y

N

Y

U

Y


Data Analysis

Data from the selected studies $(\mathrm{N}=9)$ was extracted by one reviewer into table constructed in MS Word and the sensitivity/specificity were extracted as provided in the selected articles.

\section{RESULTS}

\section{Search and review results}

The electronic search yielded 675 published articles (Fig. 1). A total of 581 articles were excluded where 371 duplicates were removed leaving 308 articles and irrelevant articles consisting of conferences, congresses, editorials, commentaries, reviews, news and old articles $(<2007)$ were removed $(n=210)$, leaving 94 articles.

The 94 articles which remained were then screened for relevancy by the reviewer using the inclusion criteria, excluding a further 75 articles [Participants were not pregnant $(n=62)$, Outcome was not postpartum depression $(n=13)$ ], leaving 19 articles. Another 10 articles were further excluded because 6 studies did not mention the gold standard used in the studies and 4 studies were excluded because the component of psychometric measurements (sensitivity and specificity) were not reported. The flow of the selected studies is shown in Figure 1.

All of the articles selected were validation study and published between 2007 until 2017. All 9 articles were rated for quality by reviewer. Overall the quality was ranked from adequate to excellent where three papers were categorized as excellent andsix papers were good in quality. All articles selected (as shown in Table 2) clearly described the inclusion criteria for the sample and reported the index test as independent of the gold standard. All sample used random sampling.

\section{Screening instruments for postpartum depression}

The articles selected included five screening tools which were Beck Depression Index (BDI), Centre for Epidemiologic Studies Depression Scale (CESD), Patient Health Questionnaire-9 (PHQ-9), Pregnancy Risk Assessment questions (PRAMS-6) and Edinburgh Postnatal Depression Scale (EPDS).

Five studies $(n=5)$ used a single screening instrument while four $(n=4)$ used combination of two or three instruments. The EPDS tool was the most widely used instrument which is in 7 out of 9 studies (4 single studies and 3 combination studies). The MINI was the most widely used gold standard being used in four of the 9 studies.

In assessing the accuracy of screening instruments in detecting depression among pregnant women, sensitivity and specificity of the instruments were assessed.For screening measures in psychological research, $80 \%$ of sensitivity and specificity indicates high accuracy of the measuring tool (Davis et al, 2013).

\section{a. Beck Depression Inventory (BDI), 2 instruments}

BDI have 21 items of self reporting with 4-point Likert rating scale with scores ranging from $0-63^{19}$. The BDI was originally developed to assess for depression severity and has been translated in various language (Finnish, French and Korea). However the tool has been criticised for use in postpartum women because of its reliance on somatic symptoms of depression, which was reported to have overlapping with physical symptoms during postpartum period ${ }^{20}$. In this review, two studies used $\mathrm{BDI}^{14,18}$. Using cut-off point between 11 and 14 , it has sensitivity rangingbetween $86.7 \%$ to $88.9 \%$ and specificity ranging between $78.5 \%$ to $88.2 \%$.

\section{b. Centre for Epidemiologic Studies Depression Scale (CES-D), 2 instruments}

CES-D consists of 20 item measuring depressive symptoms with total score ranging from 0 to 60 which reflect the level of depressive symptoms ${ }^{21}$. In this review, 2 studies used CES-D as screening tool. At cut-off point of 17 and 21, the sensitivity reported were between 72.7 to 82.6 and specificity were between 78.5 to $88.2^{14,16}$.

\section{c. Patient Health Questionnaire-9 (PHQ-9)}

The PHQ-9 contains nine items that assess each of the symptoms that comprise in the DSM-IV diagnostic criteria. Respondents were asked to rate items pertaining to loss of interest, depressed mood, sleep disruption, fatigue, changes in appetite, guilt and feeling of worthlessness, changes in concentration, psychomotor retardation/agitation and suicide. Total items were added and scored. In this review only 1 study used PHQ-9 as screening tool and 10 as cut-off point, the sensitivity was $80.0 \%$ and specificity was $72.0 \%{ }^{17}$.

\section{d. Pregnancy Risk Assessment questions (PRAMS-6); 1 instrument}

PRAMS-6 is a six item scale developed by Centers for Disease Control (CDC) to assess prevalence of perinatal health problem. In this review only one study using PRAMS-6 as screening tool. At cut-off point of 15 , the sensitivity was $80 \%$ and specificity was $73 \%{ }^{17}$.

\section{e. Edinburgh Postnatal Depression Scale (EPDS); 7 instruments}

EPDS is a 10-item questionnaire that was developed to identify women who have 
postpartum depression. In this screening tool, women were asked to rate how they have felt in the previous 7 days. Total score ranging between 0 to 30. A cut-off for possible depression at $9 /$ $10^{22}$. In this review, EPDS was the most validated instrument used to screen for postpartum depression. At cut-off point ranging between eight to twelve, the sensitivity was reported between $85.7 \%$ to $92.0 \%$ and specificity ranging between $47.7 \%$ to $95.6 \%^{10-16,18}$. EPDS is only a screening instrument and a subsequent clinical diagnosis must be made by an appropriately trained health professional. The EPDS has been translated into, and validated in, many languages other than English. The EPDS has also been validated as a screening tool for APD in pregnant women ${ }^{22}$.

The general description of the studies is as shown in Table 3. The table summarized that EPDS and BDI has sensitivity more than $80 \%$ which indicates higher accuracy as measuring tool for screening of postpartum depression. However, heterogeneity offindings was found in the specificity.

Figure 1: Study Flow based on STARD guideline

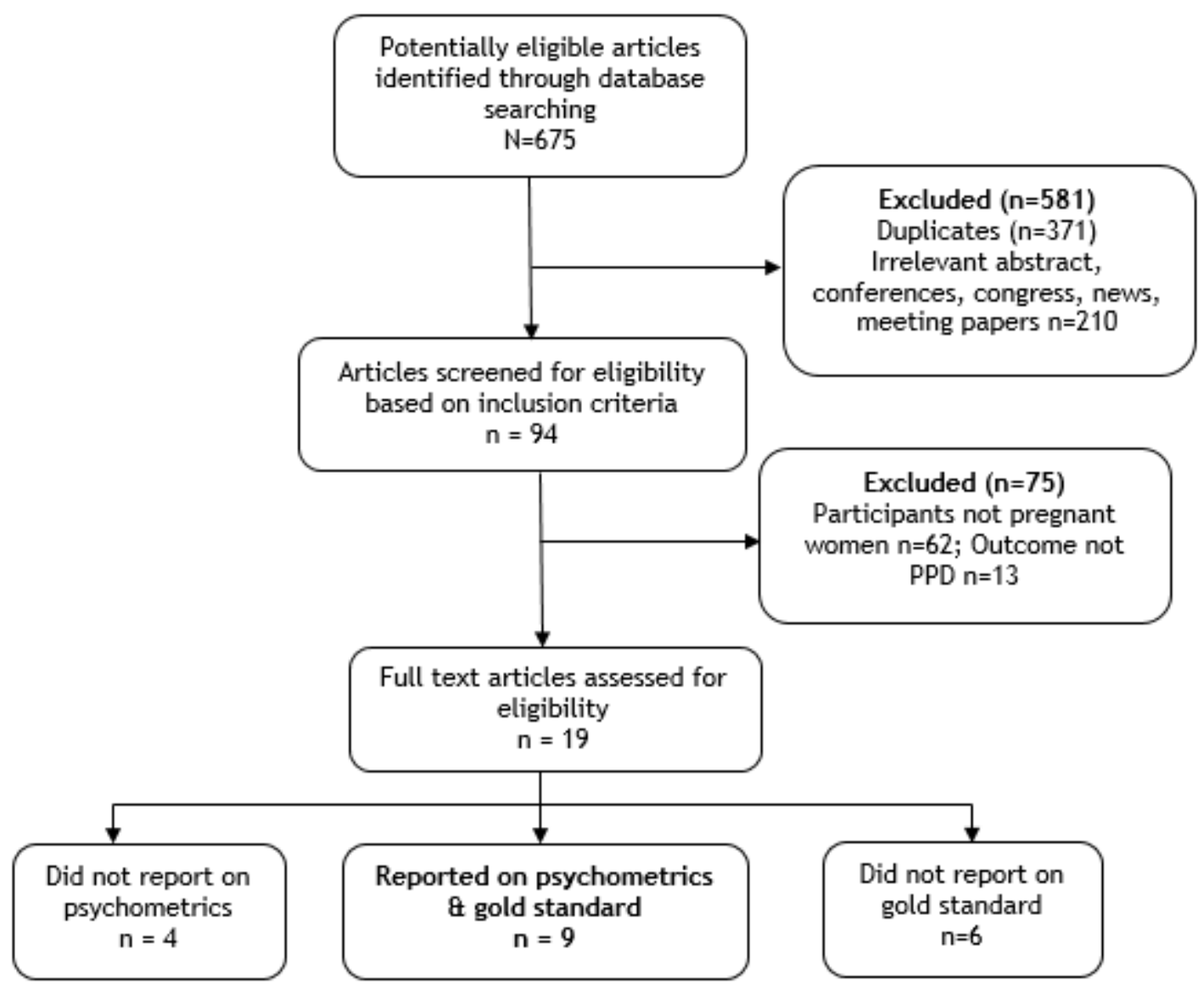




\section{DISCUSSION}

Screening for all mothers maximizes the likelihood of prompt identification of PPD. Several screening instruments have been used in clinical practice to identify PPD, for example the Patient Health Questionnaire 9 (PHQ 9), Edinburgh Postpartum Depression Scale (EPDS), Beck Depression Inventory (BDI) and the Centre for Epidemiologic Studies Depression Scale (CES-D). With the exception of the Patient Health Questionnaire 9 and the Edinburgh Postpartum Depression Scale, other instruments have at least 20 questions which require more time to complete. Lesser time to complete is more desirable to be used in primary health care.

In this systematic review, we have identified 9 studies with 5 different instruments. Among the studies, we found that EPDS was the most commonly validated instrument. The findings in this study showed that EPDS has a sensitivity more than $80 \%$ which indicates that it has higher accuracy to screen postpartum depression. High sensitivity is required in a screening test in order to not miss the cases with the disease and to reduce the number of false-positives that will have to undergo further evaluation. A study conducted among 148 pregnant mothers in Portugal reported that EPDS has high sensitivity and specificity in screening for PPD during antenatal and postnatal. It also have an area under curve (AUC) of 0.83 (95\% C.I. = 0.76-0.899, $\mathrm{p}<0.001)$ indicating an excellent classification accuracy power. The sensitivity and specificity at a cut-off $\geq 9$ was $73.7 \%$ and $70.0 \%$ respectively ${ }^{26}$. Another study in France among 60 antenatal women also reported high sensitivity and specificity for EPDS tool (sensitivity 80\%; specificity $80 \%$ ). Its validity as an index of severity of depression was also good as well as internal consistency and reliability. Similar findings were also reported in many other studies indicating high sensitivity of EPDS ${ }^{15,27,28,29,30}$.

However in this review, presence of heterogeneity was observed on the specificity between studies selected. The heterogeneity across studies could be the result of methodological differences in validation of the instruments. In addition, these studies were conducted across continents and settings with different cultures, languages and resources. The studies selected mostly were validation study across different continents with sample size ranging between 95 to 200 mothers and they were low to moderate socioeconomic status.

EPDS instrument has been used extensively in other parts of the world like the United Kingdom, Australia, Germany, Chile, Italy, South Africa, Netherlands, Sweden, Hong Kong and Saudi Arabia. Our findings and those derived from overseas studies especially outside the United Kingdom provide support for validity of the EPDS in different cultural settings ${ }^{15,27,28,29,30}$. Thus, this study offered empirical evidence to support the use of EPDS as a screening tool for detection of postpartum depression.

The limitation of this review, articles selected were only in English language, therefore other validation study in other language were not included. We also did not include studies with instruments which had been used to measure whole range of psychological morbidity such as anxiety or stress, we only focusing on depression therefore we may have not included other instruments. 
Table 2: Articles selected

\begin{tabular}{|c|c|c|c|c|c|c|c|c|c|}
\hline Author & Country & $\begin{array}{l}\text { Study } \\
\text { Design }\end{array}$ & $\begin{array}{c}\text { Sample } \\
\text { size }\end{array}$ & $\begin{array}{c}\text { Gold } \\
\text { Standard }\end{array}$ & $\begin{array}{l}\text { Screening } \\
\text { Instrument }\end{array}$ & $\begin{array}{l}\text { Cut- } \\
\text { off }\end{array}$ & Sens & Spec & Prev \\
\hline $\begin{array}{l}\text { 1. Husain et } \\
\text { al, } 2014\end{array}$ & Pakistan & Validation & 237 & $\begin{array}{c}\text { SCAN } \\
\text { interview }\end{array}$ & EPDS & 8 & 100.0 & 55.1 & $16.8 \%$ \\
\hline $\begin{array}{l}\text { 2. Venkatesh } \\
\text { et al, } \\
2014\end{array}$ & USA & Validation & 106 & $\begin{array}{l}\text { KID-SCID } \\
\text { interview }\end{array}$ & EPDS & 9 & 90.0 & 85 & $12.4 \%$ \\
\hline $\begin{array}{l}\text { 3. Alvarado } \\
\text { et al, } \\
2014\end{array}$ & Mexico & Validation & 158 & $\begin{array}{c}\text { MINI } \\
\text { Interview }\end{array}$ & EPDS & 8 & 83.8 & 68.6 & $13.1 \%$ \\
\hline $\begin{array}{l}\text { 4. El- } \\
\text { Hachem } \\
\text { et al, } \\
2014\end{array}$ & Lebanon & Longitudinal & 228 & $\begin{array}{c}\text { MINI } \\
\text { Interview }\end{array}$ & EPDS & 7 & 89.5 & 47.7 & $12.8 \%$ \\
\hline $\begin{array}{l}\text { 5. Bhusal et } \\
\text { al, } 2014\end{array}$ & Nepal & Validation & 346 & $\begin{array}{l}\text { Interview } \\
\text { ICD10 }\end{array}$ & EPDS & 12 & 92 & 95.6 & $17.1 \%$ \\
\hline $\begin{array}{l}\text { 6. Natamba } \\
\text { et al, } \\
2014\end{array}$ & Uganda & Validation & & $\begin{array}{c}\text { MINI } \\
\text { Interview }\end{array}$ & CES-D & 17 & 72.7 & 78.5 & $28.7 \%$ \\
\hline \multirow{3}{*}{$\begin{array}{l}\text { Tandon et } \\
\text { al, } 2012\end{array}$} & \multirow{3}{*}{ USA } & \multirow{3}{*}{ Validation } & \multirow{3}{*}{95} & \multirow{3}{*}{$\begin{array}{c}\text { SCID } \\
\text { interview }\end{array}$} & EPDS & 11 & 88.9 & 91.2 & \multirow{3}{*}{$13.6 \%$} \\
\hline & & & & & CES-D & 21 & 82.6 & 88.2 & \\
\hline & & & & & BDI & 14 & 88.9 & 92.7 & \\
\hline \multirow{2}{*}{$\begin{array}{l}\text { 8. Davis et } \\
\text { al, } 2014\end{array}$} & \multirow{2}{*}{ USA } & \multirow{2}{*}{ Validation } & \multirow{2}{*}{1392} & \multirow{2}{*}{$\begin{array}{c}\text { SCID } \\
\text { interview }\end{array}$} & PHQ-9 & 10 & 80.0 & 72.0 & \multirow{2}{*}{$21 \%$} \\
\hline & & & & & PRAMS-6 & 15 & 80.0 & 73.0 & \\
\hline $\begin{array}{l}\text { 9. Martin et } \\
\text { al, } 2015\end{array}$ & Brazil & Validation & 807 & $\begin{array}{c}\text { MINI } \\
\text { Interview }\end{array}$ & $\begin{array}{c}\text { EPDS } \\
\text { BDI }\end{array}$ & $\begin{array}{l}10 \\
11\end{array}$ & $\begin{array}{l}81.1 \\
86.7\end{array}$ & $\begin{array}{l}82.7 \\
73.8\end{array}$ & $17.7 \%$ \\
\hline
\end{tabular}

*Sens=sensitivity; Spec=specificity; Prev=prevalence

Table 3: General description of the studies included in the systematic review

\begin{tabular}{lllcc}
\hline No & Instrument & \multicolumn{1}{c}{ Author } & Sensitivity & Specificity \\
\hline 1. & EPDS & Husain et al, 2014 & & \\
2. & EPDS & Venkatesh et al, 2014 & & \\
3. & EPDS & Alvarado et al, 2014 & & \\
4. & EPDS & El-Hachem et al, 2014 & & \\
5. & EPDS & Bhusal et al, 2014 & & \\
6. & EPDS & Tandon et al, 2012 & & \\
7. & EPDS & Martin et al, 2015 & & \\
8. & CES-D & Natamba et al, 2014 & $72.6 \%$ & \\
9. & CES-D & Tandon et al, 2012 & & $78.5 \%-92.7 \%$ \\
10. & BDI & Tandon et al, 2012 & & \\
11. & BDI & Martin et al, 2015 & $86.7 \%-88.9 \%$ & $73.8 \%-92.7 \%$ \\
12. & PHQ-9 & Davis et al, 2014 & & \\
13. & PRAMS-6 & Davis et al, 2014 & $80.0 \%$ & $72.0 \%$ \\
\hline
\end{tabular}

\section{CONCLUSION}

In summary, we have identified 5 different instruments used to screen for postpartum depression. The EPDS was the most validated instrument in the review and we found that EPDS and BDI have higher accuracy to screen postpartum depression because the sensitivity reported were more than $80 \%$. However the assessment of specificity across several studies indicated that there was an evidence of heterogeneity. 


\section{ACKNOWLEDGEMENT}

The authors also would like to thank Department of Community Health Universiti Putra Malaysia for their institutional support throughout this review. We would like to thank the Director General of Health Malaysia for his permission to publish this article.

\section{REFERENCES}

1. Weinberg MK, Tronick EZ. Emotional characteristics of infants associated with maternal depression and anxiety. Pediatrics, 1998; 102: 1298-1304.

2. Brand SR, Engel SM, Canfield RL. The Effect of Maternal PTSD Following in Utero Trauma Exposure on Behavior and Temperament in the 9-Month-Old Infant. Ann. N. Y. Acad. Sci. 2006:1071(1): 454-458.

3. O'Connor TG, Heron J et al. Antenatal anxiety predicts child behavioral/emotional problems independently of postnatal depression. Journal of the American Academy of Child \& Adolescent Psychiatry. 2002; 41(12): 14701477.

4. Rahman A, lqbal Z, Bunn J, et al. Impact of maternal depression on infant nutritional status and illness: a cohort study. Arch. Gen Psychiatry. 2004; 61(9): 946-952.

5. Gjerdingen DK, \& Yawn BP. Postpartum depression screening: importance, methods, barriers, and recommendations for practice. The Journal of the American Board of Family Medicine. 2007; 20(3): 280-288.

6. Meyer GJ. Guidelines for reporting information in studies of diagnostic test accuracy: the STARD initiative. Journal of personality assessment. 2003; 81(3): 191-193.

7. Pettersson A, Boström KB, Gustavsson $P$, et al. Which instruments to support diagnosis of depression have sufficient accuracy? A systematic review. Nordic journal of psychiatry. 2015; 69(7): 497-508.

8. Chorwe-Sungani G, \&ChippsJ.. A systematic review of screening instruments for depression for use in antenatal services in low resource settings. BMC psychiatry. 2017; 17(1): 112 .

9. Whiting $P$, Rutjes AW, Reitsma JB, et al. The development of QUADAS: a tool for the quality assessment of studies of diagnostic accuracy included in systematic reviews. BMC medical research methodology. 2003; 3(1): 25.
10. Husain N, Rahman A, Husain $M$, et al. Detecting depression in pregnancy: Validation of EPDS in British Pakistani mothers. Journal of immigrant and minority health. 2014; 16(6): 1085-1092.

11. Venkatesh KK, Zlotnick C, Triche EW, et al. Accuracy of brief screening tools for identifying postpartum depression among adolescent mothers. Pediatrics. 2014; 133(1): e45-e53.

12. Alvarado-Esquivel C, Sifuentes-Alvarez A, \& Salas-Martinez C. Validation of the Edinburgh postpartum depression scale in a population of adult pregnant women in Mexico. Journal of clinical medicine research. 2014;6(5): 374378.

13. El-Hachem C, Rohayem J, Khalil RB et al. Early identification of women at risk of postpartum depression using the Edinburgh Postnatal Depression Scale (EPDS) in a sample of Lebanese women. BMC psychiatry. 2014; 14(1): 242.

14. Natamba BK, Achan J, Arbach A, et al. Reliability and validity of the center for epidemiologic studies-depression scale in screening for depression among HIV-infected and-uninfected pregnant women attending antenatal services in northern Uganda: a cross-sectional study. BMC psychiatry. 2014; 14(1): 303.

15. Navarro P, Ascaso C, Garcia-Esteve L, et al. Postnatal psychiatric morbidity: a validation study of the GHQ-12 and the EPDS as screening tools. General Hospital Psychiatry. 2007; 29(1): 1-7.

16. Tandon SD, Cluxton-Keller F, Leis J, et al. A comparison of three screening tools to identify perinatal depression among lowincome African American women. Journal of affective disorders. 2012; 136(1): 155-162.

17. Davis K, Pearlstein T, Stuart $\mathrm{S}$, et al Analysis of brief screening tools for the detection of postpartum depression: comparisons of the PRAMS 6-item instrument, PHQ-9, and structured interviews. Archives of women's mental health. 2013; 16(4): 271-277.

18. Martins CDSR, dos Santos Motta JV, Quevedo LA, et al. Comparison of two instruments to track depression symptoms during pregnancy in a sample of pregnant teenagers in Southern Brazil. Journal of affective disorders. 2015; 177: $95-100$.

19. Beck AT, Ward CH, Mendelson $\mathrm{M}$, et al. An inventory for measuring depression. Arch. Gen. Psychiatry. 1961; 4(6): 561-571. 
20. Boyd RC, Le HN, \&Somberg R. Review of screening instruments for postpartum depression. Archives of women's mental health. 2005: 8(3): 141-153.

21. Radloff L. Scale: A self-report depression scale for research in the general population. J ClinExpNeuropsychol. 1997;19:340-56.

22. Gibson J, McKenzie-McHarg K., Shakespeare J, Price J, \&Gray R. A systematic review of studies validating the Edinburgh Postnatal Depression Scale in antepartum and postpartum women. ActaPsychiatr Scand. 2009; 119(5): 350-364.

23. Eberhard-Gran M, Eskild A, Tambs K, et al.. Review of validation studies of the Edinburgh Postnatal Depression Scale. ActaPsychiatr Scand. 2001; 104(4): 243-249.

24. Tsai AC, Scott JA, Hung KJ, et al. Reliability and validity of instruments for assessing perinatal depression in African settings: systematic review and meta-analysis. PLoS One. 2013; 8(12): e82521.

25. Herman $C$. What makes a screening exam good?.Virtual Mentor. 2006 Jan 1;8(1):34-7.

26. Santos IS, Matijasevich A, Tavares BF, Barros AJ, Botelho IP, Lapolli C, Magalhães PV, Barbosa AP, Barros FC. Validation of the Edinburgh Postnatal Depression Scale (EPDS) in a sample of mothers from the 2004 Pelotas Birth Cohort Study. Cadernos de Saúde Pública. 2007;23:2577-88.

27. Cox JL, Chapman G, Murray D, Jones P. Validation of the Edinburgh Postnatal Depression Scale (EPDS) in non-postnatal women. Journal of affective disorders. 1996 Jul 29;39(3):185-9.

28. Garcia-Esteve L, Ascaso C, Ojuel J, Navarro P. Validation of the Edinburgh postnatal depression scale (EPDS) in Spanish mothers. Journal of affective disorders. 2003 Jun 1;75(1):71-6.

29. Rubertsson C, Börjesson K, Berglund A, Josefsson A, Sydsjö G. The Swedish validation of Edinburgh postnatal depression scale (EPDS) during pregnancy. Nordic journal of psychiatry. 2011 Dec 1;65(6):414-8.

30. Kadir AA, Nordin R, Ismail SB, Yaacob MJ, Mustapha W, Rushidi WM. Validation of the Malay Version of Edinburgh Postnatal Depression Scale for Postnatal Women in Kelantan, Malaysia. Asia Pacific Family Medicine. 2004 Jan 1;3. 